\title{
Postgraduate education in taxation by means of a flexible learning model: A new educational paradigm
}

\author{
HP Wolmarans \\ Department of Accounting and Finance \\ University of Pretoria
}

\begin{abstract}
The Internet is becoming increasingly important in our daily lives. So, too, is the ease of communication by means of television. The power of these two technological tools in education has been combined in so-called 'flexible learning'. This study investigates the experience of students in a master's degree programme in taxation, which is presented by means of flexible learning. In general, students experience this mode of learning very positively and would advise others to enrol for the same course. They acknowledge that the benefits of flexible learning far exceed any possible drawbacks.
\end{abstract}

\section{Key words}

Flexible learning

Telematic education

Postgraduate education in taxation

\section{Introduction}

The past ten years have seen explosive growth in the computer technology used for learning in schools, universities, businesses, industry and the professions (Alessi and Trollip 2001:ix). Distance learning and the Web are two of the most rapidly developing areas in the information technology arena (Whalen and Wright 2000:xi). At the University of Pretoria, sound progress has already been made with educational innovation, which is increasingly becoming student-oriented and learning-centred, and the creation of flexible learning environments (Brown 1999:3). One of the many courses that can be taken in the flexible learning mode is a master's degree in taxation (University of Pretoria 2001). Various aspects of flexible learning and students' experience of these aspects are investigated in this study. 
In part two of this study, the background to the problem is described, while in part three the problem to be addressed is formulated in three questions. The study aims to find answers to these questions. Part four reports on a literature survey; part five contains a theoretical framework and assumptions; and part six attempts to determine the profile of the typical student that enrols for the course, despite the availability of alternatives. Part seven reports on students' experience of the medium by means of which the course is presented, while some conclusions and recommendations are articulated in part eight. In part nine, areas in need of research are identified.

\section{Background}

There is an increasing reliance worldwide on modern technology in education. For instance, Web-based training is set to transform the world of education and training (Steed 200:1). The increasing reliance on technology in education is especially applicable in distance education, where students are often not able to attend classes on a regular basis. At the University of Pretoria, the Department of Accounting and Finance has been presenting a master's degree course in taxation by telematic means since the beginning of 1999. Telematic education (tele: over a distance; and -matic: by means of) refers to the way in which effective and efficient flexible learning environments are created for students. Students are selected, mainly on the basis of their academic background, and, in order to maintain high standards, only a limited number of students are admitted to the course each year.

While the Internet is used to communicate with students and to provide them with lecture notes and study material, television time has been bought to broadcast a total of 20-25 lectures of one hour each per year. These lectures are presented by highly respected specialists in taxation and broadcast weekly or bi-weekly. Probably the greatest advantage for students is that respected practitioners have agreed to present lectures on selected subjects. The lectures are recorded at the practitioners' convenience and then broadcast in a prearranged time slot. If the education system had been based on contact-education sessions, the presentation of the lectures would probably not have been possible on such a large scale, because of the limitation of resources. By allowing guest lecturers to share their practical knowledge with students, the knowledge base of the University is extended. Should a student should miss a broadcasted lecture, he or she can purchased a video of the lecture for a nominal amount.

Students are required to have access to Internet facilities. While most students indicated that they have access to the Internet at their place of work, large percentages also have access to the Internet at home. In addition, facilities for access are available on campus at the WebCT laboratory. This is where students can attend information sessions at the 
beginning of the course on how to use WebCT. A WebCT user's guide, in the form of an information booklet, is provided to each student. An excellent online help function is available, and students can request assistance from a help centre by e-mail. In WebCT, discussion boards are available for students to put questions that are answered in less than 48 hours. Questions and answers can then be read by all participating students. In the 'chat room' facility, students can exchange ideas with fellow students that are simultaneously connected to the facility.

If students should have additional questions to ask, administrative staff can be reached by telephone. If the issue cannot be resolved by telephone, an appointment can be made with a member of staff. The extent of assistance available to students indicates that it is important to the co-ordinators of the course that students should receive professional assistance whenever a question arises. At the University of Pretoria, workshops are arranged at which students and lecturers interact and discuss unresolved issues.

A multidisciplinary approach is used in terms of which both the Department of Accounting and Finance and the Department of Commercial and Labour Law collaborate in presenting the lectures. Students can study for either the MCom(Taxation) degree or the $\operatorname{LLM}$ (Taxation) degree, depending on their area of specialisation. The duration of the degree course is two years, but students can enrol for a third year to complete the dissertation if they should need more time to do so. During each of the two years of study, students receive seven case studies as assignments of which they have to complete five. Some of the assignments may be done in a group context. A test that is administered in June, comprises two more case studies. Model answers for these nine case studies are posted on the Internet, and are used by students in their preparation for the year-end examination. Students combine this rather hectic academic schedule with their career and family responsibilities. It is therefore not surprising that some students prefer to postpone the dissertation to a third year of study in order to do justice to it.

\section{Statement of the problem and aim of this study}

A number of questions arise from the above, namely:

1. Can flexible learning be justified in terms of the available literature?

2. Which students typically enrol for the course concerned?

3. How do students experience the delivery mode of the course?

This study aims to find answers to the above questions and consists of three parts. The first part attempts to justify telematic education by means of a literature survey on an international basis. The second part 
focuses on the characteristics of the postgraduate students enrolled for a master's degree course in taxation, which is used as an example of a course that has been presented successfully for a number of years. In the third part, an opinion survey is reported, which was undertaken among the students to gauge their experience of the medium by means of which the course is delivered.

The results of this investigation could be important for both the coordinators of the course and for any tertiary education institution that aims to use this innovative approach to education. It could also be important for any student that wants to enrol for a telematic course to know what to expect of a course of this nature.

\section{$4 \quad$ Literature survey}

\subsection{The importance of the Internet for education}

Cronjé (1997:149) considers the Internet to be the fastest-growing facet of information technology in the world, which has widely explored commercial and educational possibilities. The quick and reliable delivery of mail messages makes the Internet the ideal medium for distance communication. Cronje and Clarke (1999:213) agree that the ease with which Internet communication can take place over a distance makes it an effective medium for co-operative learning in a distance-learning environment. Whalen and Wright (2000:xi) consider the growth of the Internet to be largely the result of the following characteristics, which are also the features that make the Internet very attractive for educational purposes:

- $\quad$ Continually increasing multimedia capabilities;

- $\quad$ broad geographical accessibility; and

- $\quad$ the number and sophistication of users.

Use of the Internet to support learning and teaching is growing exponentially as more and more educational organisations are recognising the potential that it possesses (Jefferies and Hussain 1998:359). The Internet is increasingly being used by students to gather a variety of data and to gain an extensive range of experiences as part of their learning process.

Web-based training produces many efficiencies such as reduction in the cost of training delivery; speed in updating course material; flexibility in the time and geographical location of course delivery; and the ability to manage training to ensure that corporate and individual needs are met (Whalen and Wright 2000:27). These efficiencies are especially important at present, because knowledge workers have ongoing needs for both information and updated skills to enable them to respond to challenging and constantly changing job demands. Alberts (2000:9) 
remarks that a Web-based course can never be regarded to be complete as far as its design and development is concerned. As feedback is received during the presentation of the course, lecturers reflect on their efforts, new developments occur in the content field and, as information and computer technologies improve, the course is constantly redesigned and redeveloped. The lecturers involved continually improve their skills, and the learning experience for students is enriched.

With the use of electronic communication for educational delivery and interaction, Web-based higher education is growing rapidly as a field of practice. This innovative approach to higher education has broad appeal for many higher educational institutions. For example, in 2000, the WebCT educational system was used in 1150 higher educational institutions worldwide with an estimated 5,2 million students in 51 countries benefiting from the system (WebCT 2000:5).

Driscoll (1998:9) emphasises that the characteristics of adult learners should be borne in mind when Web-based courses are designed. These courses should be learner-centred and designed to totally engage the learners and draw on their experiences. Kozma (1994:18) agrees with this view, but stresses that the following question should be asked continuously: "In which ways can we use the capabilities of media to influence learning optimally for particular students, tasks, and situations?"

\subsection{The combination of distance education and conventional education}

There is hardly a residential university or technikon in South Africa, which in the past had limited education to the borders of its campus, that is not moving towards the delivery of programmes to remote areas (Smit 1999:2). These educational programmes are usually delivered in accordance with a distance-education model or in a combination of contact education and distance education. Several educational institutions have already invested in studios for interactive television broadcasts, computers, learning centres and additional facilities to print learning material. Tait and Mills (1999:1) remark that the drive towards combining distance education and conventional education is taking place with a rapidity that is bewildering from all perspectives. This has lead to a blurring of the distinction between distance education and conventional education.

\subsection{Flexible learning as a solution}

Open learning is a philosophy of education that is concerned with the pursuit and promotion of matters such as access, accessibility, equity and openness (Brown 1999:11). Lifelong learning emphasises the fact that learning is a continuous process that occurs regardless of where the 
learner is and continues for the duration of the learner's life. Flexible learning is a macro concept, which encompasses both open learning and lifelong learning and is student-oriented, learning-centred and flexible. Nunan (1996:1) views flexible learning as a user-centred approach to learning, which has a capacity to cater for a wider variety of learning styles and patterns than conventional learning approaches.

While flexibility is generally perceived to refer to students' choice of the place of study (for example on campus, at home, in a learning centre or in the work environment), many more aspects are involved. Collis (1999:373) identifies at least 23 other aspects of flexibility that can be associated with individualised instruction. These matters refer to flexibility in respect of for example, time, content, entry, completion, instructional approach, learning resources, use of technology, interactivity and communication.

One example of the increasing use of flexible learning for distance education is to be found in Australia, which has a wide geographical dispersion of its population, posing special educational problems in respect of delivery (Oliver and Reeves 1996:45). Two forms of telematics, namely audio-graphics and live interactive television, are used. Audio-graphics involves two telecommunication links, one that connects computers via modems and a second link that provides an audio-conferencing medium through a normal telephone connection. Live interactive television involves the combination of a one-way television signal with a toll-free call-back telephone, enabling students to communicate directly with the lecturer during programme transmission.

\subsection{Financial aspects of flexible learning}

Governments worldwide increasingly demand the provision of effective learning environments in accordance with students' needs and formally acknowledge the role of distance education and technology-enhanced education (Swift, Wilson and Wayland 1997:85). The main reason for this demand appears to be cost-effectiveness, because, although distance-education technology can be costly, a great number of students can be served effectively. Therefore, one of the primary reasons for its increased popularity is undoubtedly financial in nature.

Whalen and Wright (2000:56) believe that cost-benefit analyses should be done to determine, for each specific course, whether the development of a Web-based programme is justified. To achieve savings for Webbased courses in comparison with classroom courses requires a sufficient number of students to recover course development costs. Experience also reveals that Web-based training has significantly higher fixed costs than classroom-based training. However, the higher course development costs are offset by lower variable costs in course delivery. 
The measurement of the cost of courses is an area that requires further study.

From a financial viewpoint, educational innovation is a necessity (Brown 1999:5). Universities have resource limitations that necessitate the optimisation of resources and require that they address the demands of mass education and training. The well-known exhortation "to do more with less" echoes frequently in the corridors of universities. Universities are faced with the need to make education more cost-effective and to simultaneously enhance the quality of learning.

For example, students demand more flexibility with regard to time, place, pace and mode of study, which suits their specific circumstances; wider acceptance and portability of qualifications; and more say in programme compilation and the general content of the degree course that they are studying to prepare them for the market they will enter after graduating. Universities should be able to provide for the changing needs of students without making structural changes and within a short time. Flexible learning is one such change and, within flexible learning, changes made to meet the market demand are, by definition, easier to effect than in the case of more traditional, less flexible methods of teaching.

As a result of the availability of the Internet and other technological resources, promising postgraduate students enrol at foreign universities, and South African universities lose these potential students (Smit 1999:4). Private universities are increasingly concentrating on postgraduate students and use technology to recruit and service these students worldwide. This trend could have serious financial implications for the traditional universities that also (but often unsuccessfully) attempt to attract the best postgraduate students available.

Universities are entering an era of global competition for the best students. This competition will end the monopoly on knowledge creation and dissemination that universities have had (Tsichritzis 1999:94). Information and communication technologies make it possible for students in any country to gain internationally recognised qualifications from educational institutions that operate in their area. Students will furthermore be prepared to pay high fees, because they know that they will be treated as valued clients.

\subsection{Universities of the future}

Gibbons (1998:ii) argues that cost-effectiveness is becoming increasingly important for universities and that it will compel universities to think differently about intellectual resources. In order to operate efficiently, universities will probably become smaller and will have to learn to manage the intellectual property that they do not fully control.

Meditari Accountancy Research Vol. 9 2001: 333-349 
Hall (1998:147) considers the use of telematics to create a "virtual university" to be the key to meeting the escalating demands for higher education with declining resources. In February 1997, the World Bank launched its African Virtual University (AVU, with initial test sites at universities in Addis Ababa and Dakar), with the aim of providing muchneeded courses in science, technology and business science. Franchises will be set up on traditional campuses in sub-Saharan Africa to address what the bank considers to be the fatal impassé of underfunding, declining standards and failure to meet the educational needs of rapidly growing populations.

The rise of the 'corporate virtual university' (CVU), especially in the USA, is attributed to the rapid pace of change and the need to ensure that learning is firmly aligned with business needs (Teare 2000:54). The goal of a CVU is to connect the career-long learning capabilities of the organisation's human resources to the agenda for change. Rather than simply requiring high-potential managers to attend external executive education programmes, these organisations are developing focused, large-scale, Internet-resourced, customised, action-learning programmes that have measurable results. Rather than considering CVU's to be a threat to its traditional education programmes, the university of the future should find creative ways of collaborating with these corporations to provide learning that serves their business needs.

Tsichritzis (1999:93) is of the opinion that the university of the future will be defined by means of new concepts. The Internet makes electronic classrooms possible, while digital libraries provide knowledge repositories. The Web offers up-to-date material for seminar discussions, while computer simulation substitutes for laboratories. Technology should therefore not be considered to be merely an add-on service as were computers and audio-visual products in the past - it touches the very substance of a university, which is the development and transfer of knowledge. A complete re-engineering has to occur in order to maintain the spirit of the university as being an intellectual watering hole.

\subsection{Conclusion}

It appears that information and communication technologies are very important for effective distance education. A flexible learning approach, which combines contact education and distance education for the convenience of adult students, may be the answer. Cost-effectiveness appears to be the main reason for the increasing popularity of flexible learning, because once an efficient system has been established, a great number of students can be served effectively by the system. As Whalen and Wright (2000:161) have remarked, flexible learning is likely to become very widespread - and the delivery mode of choice for many educational institutions. 


\section{Theoretical framework for and assumptions of this study}

\subsection{Is it important to evaluate the impact of e-learning?}

The term e-learning can be used to describe any form of learning that uses the Internet as a medium, whether it be partially (as with flexible learning) or comprehensively. Strong arguments can be advanced for the evaluation of any form of e-learning. The reasons for the evaluation of e-learning coincide with the classical reasons for the evaluation of any type of learning experience (Phillips et al 2000:1). The most important of these reasons are:

- $\quad$ To determine whether e-learning is accomplishing its objectives.

- To identify the strengths and weaknesses in the e-learning process.

- $\quad$ To determine the benefit/cost ratio of an e-learning solution.

- To collect data that can be used in the marketing of future initiatives.

In addition, the technology aspects of e-learning raises other demands for evaluation, namely:

- The tremendous cost of technology often demands accountability, including the measurement of the actual return on investment.

- $\quad$ The novelty that e-learning has for many groups brings about pressure for information on its effectiveness and efficiency as a learning solution.

- Because e-learning is not a proven process in many organisations, there is a need to demonstrate value immediately rather than when it becomes a routine process.

According to Phillips et al (2000:6), the most important differences between the evaluation of e-learning and traditional learning are:

- The collection of data for measuring reaction to the delivery mode and the learning that takes place can be built into the process much easier than in the case of traditional methods.

- $\quad$ Because some e-learners are located in remote areas, some of the methods of data collection, such as focus groups and direct observation, are more difficult to use.

\subsection{Various levels of evaluation}

Evaluation of e-learning is a complex issue. Various types of data should be collected when a comprehensive evaluation is called for. The type of 
data needed often depends on the purpose of the evaluation and the individuals that require the data. The various types of data collected can be classified into the following five levels that are listed by Phillips et al (2000:9) (the first four were developed by Kirkpatrick in the 1950's):

1. Measure participant reaction to the programme and capture planned actions during the actual learning activity.

2. Measure changes in knowledge, skills or attitudes.

3. Measure change in on-the-job behaviour and specific applications.

4. Measure changes in business impact for either individuals or work units.

5. Compare the monetary benefits of the programme to the actual cost of the programme.

Whereas this study is mainly focused on level 1 , namely the measurement of participants' reactions to the programme, some elements of level 2, concerning the attitudes of participants, are also included in it.

\subsection{Assumptions}

A basic assumption in this study is that the Internet and television will continue to be available in future to provide the type of flexible learning described. Another assumption is that adult learners, who often have to combine a demanding job, family life and a challenging study programme, will continue to be in need of flexible learning models.

\section{Which students typically enrol for the master's degree in taxation that is presented by means of flexible learning?}

In this section an attempt is made to identify the profile of the typical student that registers for the course concerned, although alternative study possibilities are available. One of the alternatives is a similar degree presented on a distance-education basis (with limited interaction), which is available anywhere in South Africa. Another alternative for students living in the Johannesburg/Pretoria area is a similar degree presented by means of contact education. Despite having these alternatives, students chose the course presented by means of the flexible learning model.

It should be borne in mind that students undergo a strict selection process that takes into account their academic career and their work experience. Only those applications that are regarded as being able to benefit most from the course are admitted. This selection process naturally leads to participants being highly qualified. 
During their first and second year of study, students on the course are required to watch the broadcast of lectures on a regular basis, complete a number of assignments each year and take a mid-year test and an examination at the end of the year. Arrangements are made for the students to write examinations at the facilities of Technikon SA, which are located in all the large cities in South Africa. Students that have not completed the dissertation by the end of the second year are permitted to enrol for one more year. This means that the first-year and secondyear students currently have direct experience of this innovative approach to education. They are therefore in the best position to comment on the learning process as they experience it.

Although questionnaires were originally distributed to all 145 students enrolled for the first, second and third year of study, a limited number of the third-year students responded. Only three (or 10\%) of the 30 thirdyear students responded, which is lower than the average (45\%) response rate for the first-year and second-year students. As a result of the low response rate of the third-year students, as well as the reasons set out above, the first-year and second-year students form the target population of this study.

The records of the 81 students enrolled for the first year and 32 enrolled for the second year of the MCom(Taxation) and LLM(Taxation) degree courses were studied to determine the typical student profile. The biographical information indicated in table 1 was considered to be important.

Table 1: Biographical information of first-year and secondyear students

\begin{tabular}{|c|c|}
\hline & Percentages \\
\hline \multicolumn{2}{|l|}{ Gender } \\
\hline Male & $60 \%$ \\
\hline Female & $40 \%$ \\
\hline \multicolumn{2}{|l|}{ Marital status } \\
\hline Married & $46 \%$ \\
\hline Single & $52 \%$ \\
\hline Divorced & $2 \%$ \\
\hline \multicolumn{2}{|l|}{ Qualifications } \\
\hline Chartered Accountant & $39 \%$ \\
\hline BCom(Hons) & $28 \%$ \\
\hline LLB or Bproc & $15 \%$ \\
\hline BCom or CFA & $10 \%$ \\
\hline Diploma or Certificate in Taxation & $8 \%$ \\
\hline \multicolumn{2}{|l|}{ Age } \\
\hline Range & 22 to 68 years \\
\hline Median & 30 years \\
\hline First and third quartile & 26 to 34 years \\
\hline
\end{tabular}


Table 1 (continued)

\begin{tabular}{|c|c|}
\hline & Percentages \\
\hline \multicolumn{2}{|l|}{ Home Language } \\
\hline Afrikaans & $58 \%$ \\
\hline English & $27 \%$ \\
\hline Other & $15 \%$ \\
\hline \multicolumn{2}{|l|}{ Undergraduate studies at } \\
\hline University of Pretoria & $40 \%$ \\
\hline University of the Orange Free State & $12 \%$ \\
\hline University of South Africa & $10 \%$ \\
\hline Potchefstroom University for $\mathrm{CHE}$ & $8 \%$ \\
\hline Other institutions & $30 \%$ \\
\hline \multicolumn{2}{|l|}{ Live in } \\
\hline Pretoria & $56 \%$ \\
\hline Johannesburg & $23 \%$ \\
\hline Less than $200 \mathrm{~km}$ from Pretoria & $4 \%$ \\
\hline More than $200 \mathrm{~km}$ from Pretoria & $17 \%$ \\
\hline
\end{tabular}

It is clear from table 1 that there are more male students than female students enrolled for the course. The percentage of single students is roughly similar to the percentage of married students. The profession best represented is that of chartered accountant (39\%), while $38 \%$ of the students have a Bcom or BCom(Honours) degree or a CFA as their highest qualification. The fact that only about $15 \%$ of the students have a background in law, could be because undergraduate law students do not have nearly as much exposure to taxation as students that have a commercial background, and therefore fewer tend to specialise in taxation.

Although a few students are older than 50 years, the median age is 30 years. A total of $50 \%$ of the students are between 26 and 34 years old, which means that the course is more popular with students that are still building a career than with older students. More than half of the students are Afrikaans speaking, but most of them indicated that they prefer the lectures to be presented in English.

Most of the students had completed their undergraduate studies at the University of Pretoria. It should, however, also be noted that a significant number of students in the sample obtained a BCom(Honours) degree, a certificate or a diploma at the University of South Africa, regardless of where they studied for the first degree.

It is also important to know where the students live and work in order to determine their geographical distribution. Nearly $80 \%$ of the students live in Pretoria or Johannesburg, while only $17 \%$ live more than $200 \mathrm{~km}$ from Pretoria. The latter students, some of whom live as far away as Durban 
and Cape Town, are most likely not able to attend the workshops that are presented.

The typical student that enrols for the course is a male, between 26 and 34 years old, equally likely to be single or married and is Afrikaans speaking, but prefers the lectures and technical terms to be in English. $\mathrm{He}$ or she has a commercial qualification and lives in Pretoria or Johannesburg. The fact that these students are mature and adult learners, most of whom are studying for a third or even a fourth degree, should be borne in mind when evaluating the success of the mode in which the course is presented.

\section{How did students experience the delivery mode used?}

The sample comprised the 32 first-year students and 20 second-year students that responded to the questionnaire sent to them by e-mail. A reminder was sent after two weeks and again after seven weeks to those students that had not yet responded. The questionnaire consisted of ten open-ended questions on various aspects of how the students experience the flexible mode of learning. Respondents were reassured that their responses would be treated as confidential and that only aggregate results would be reported. They were also offered a summary of the main results of the study upon its completion. In what follows, a summary of the responses of the 52 respondents is provided.

\subsection{The benefits of flexible learning}

When students were asked to list at least three benefits of flexible learning as they experience it, the following were identified as being the most important benefits:

- $\quad$ Flexibility, studying at your own tempo and tailoring study to professional and other commitments (76\%).

- $\quad$ Taping a lecture and watching it again, which is better than attending live lectures (51\%).

- $\quad$ Time saved by not having to travel to lectures (45\%).

- $\quad$ Convenience, such as watching a lecture from your lounge or accessing the notes and other study material on the Internet $(44 \%)$.

- Use of the latest communication technology and rapid response to questions by e-mail $(42 \%)$.

- Imposition of the discipline related to self-learning (15\%).

The flexibility of being able to watch the broadcast of lectures from convenient surroundings, in addition to the convenience of accessing study material on the Internet in one's own time from home, at work or in 
the WebCT laboratory, appears to be the greatest benefit of the medium by means of which the course is presented. Students are also pleased with the opportunity that they have to review lectures once the lectures have been taped, and they find this feature of flexible learning to be better than the attendance of live lectures. The use of modern communication technology and the ease with which questions can be asked by e-mail are also major benefits of the delivery mode used.

\subsection{Would students again enrol for this course if they had a choice?}

It can be safely assumed that, before they enrolled for this course, all students considered the alternatives mentioned in section 6 above. They nevertheless chose the course concerned. When asked whether they would again enrol for the course if they had the choice, at least $80 \%$ of the students replied positively. When asked whether they would advise other interested students to enrol for the course, approximately $90 \%$ replied that they would.

\subsection{Concerns raised by some students}

Although the majority of students experience the delivery mode of the course very positively, the concerns raised by students should also be noted and regarded as possible areas for improvement. One such concern is that students acknowledge that a student enrolled for the course could feel isolated as a result of the lack of face-to-face interaction with fellow students and the lecturer. The solution suggested for this problem is that students should be encouraged to form study groups with the groups meeting frequently.

Another concern is that students do not feel that they have a great deal of self-confidence in using WebCT to gather information and to communicate with lecturers and fellow students. It was suggested that more time should be scheduled for WebCT training at the beginning of the course. Despite these concerns, the delivery mode used for the course appears to be working well, or, in the words of one student: "Any possible drawbacks are more than compensated for by the terrific benefits of flexible learning."

\section{Conclusions and recommendation}

It is now possible to answer the questions posed in part two of the study. There appears to be a strong need internationally for an increased use of flexible learning at tertiary educational institutions that have limited resources. This innovative method of learning will probably be extended at universities that are successful in future, mainly because of its financial benefits and its ability to serve a great number of students in diverse environments. 
The typical student responded positively and would advise prospective students to enrol for the masters degree in taxation. The flexible nature of the course and the ability to combine study with professional and other commitments are the main positive aspects mentioned. Students can tape a lecture and review it later, which is better than attending live lectures. They are impressed with the use of modern communication technology as well as with the ease with which they can obtain study material from the Internet at home, at work, or wherever they wish to access the Internet.

\section{$9 \quad$ Areas for further research}

This study focuses on a master's degree course in taxation and attempts to generalise from that specific course. However, some questions remain unanswered, setting the scene for further research. One such question concerns the experience of students in similar courses that are presented by means of flexible learning.

This study also focuses on the first-year and second-year students enrolled for a course, and not on the third-year students. Some of these students report that they experience problems in respect of finalising the dissertation in order to complete the degree. The reasons why these students experience problems and the possible solutions to these problems should be investigated.

Which other students that are enrolled for a master's degree course could benefit if the degree course were presented by means of this flexible learning model? If the model is working well, it would be logical to investigate other opportunities for implementing it. A cost-benefit analysis should be undertaken for every course that is presented by means of flexible learning. What are the issues that should be taken into account when this is done from a scientific point of view?

If adult learners that are enrolled for a master's degree course report positively on their experience of a flexible learning model, what would be the experience of undergraduate students if they were to be exposed to a similar learning model? Which elements of the learning model described in this study would be most valuable for such undergraduate students? If these questions were answered, the answers could contribute significantly to the enhancement of the delivery of much needed education in South Africa. 


\section{Bibliography}

Alberts, P. 2000. Instructional design skills required by lecturers in WebCT-based courses, Unpublished research paper, University of Pretoria, Pretoria.

Alessi, S.M. and Trollip, S.R. 2001. Multimedia for learning: Methods and developments, 3rd edition, Allyn and Bacon, Boston.

Brown, T.H. 1999. Focusing on the client: Into the future with flexible learning, Unpublished discussion document, University of Pretoria, Pretoria.

Collis, B. 1999. New didactics for university instruction: Why and how?, Computers \& Education, Vol. 31, No. 4, pp.373-393.

Cronjé, J.C. 1997. Interactive Internet: using the Internet to facilitate cooperative distance learning, South African Journal of Higher Education, Vol. 11, No. 2, pp.149-156.

Cronjé, J.C. and Clarke, P.A. 1999. Teaching "teaching on the Internet" on the Internet, South African Journal of Higher Education, Vol. 13, No. 1, pp.213-226.

Driscoll, M. 1998. Web-based training: Using Technology to Design Adult Learning Experiences, Pfeiffer, San Francisco.

Gibbons, M. 1998. Higher education relevance in the 21st century, Paper presented at the UNESCO World Conference, Paris, France, pp.i-ii \& 1- 60.

Hall, M. 1998. The virtual university: Education for all, or a segregated highway?, South African Journal of Science, Vol. 94, No. 4, pp.147-150.

Jefferies, P. and Hussain, F. 1998. Using the Internet as a teaching resource, Education and Training, Vol. 40, No. 8, pp.359-365.

Kozma, R. B. 1994. Will media influence learning? Reframing the debate, Journal of Educational Multimedia and Hypermedia, Vol. 8, No. 3, pp.7-19.

Nunan, T. 1996. Flexible delivery - What is it and why is it part of the current educational debate?, Paper presented at the Higher Education Research and Development Society of Australia Annual Conference, Perth, Australia, 8-12 July 1996. 
Oliver, R. and Reeves, T.C. 1996. Dimensions of interactive learning with telematics for distance education, Education, Training, Research and Development, Vol. 44, No. 4, pp.45-56.

Phillips, J., Phillips, P.P. and Zuniga, L. 2000. Evaluating the effectiveness and the return on investment of e-learning. American Society for Training and Development, (Online).

http://www.astd.org/virtual community/ research/What works/e-

learning/e-learning main.html

Smit, P. 1999. Programme development and quality control: Implications of graduate education, Unpublished document, University of Pretoria, Pretoria, (Afrikaans).

Steed, C. 2000. Web-based training, Gower Publishing, Aldershot.

Swift, C.O., Wilson, J.W. and Wayland, J.P. 1997. Interactive distance education in business: Is the new technology right for you?, Journal of Education for Business, November/December 1997, pp.85-89.

Tait, A. and Mills, R. 1999. Convergence of Distance and Conventional Education, Routledge, London.

Teare, R. 2000. Modelling the Virtual University. Chapter 5, pp.53-72 in Prestoungrange, G., Sandelands, E. and Teare, R. The virtual learning organization: Learning at the workplace campus, Continuum, London.

Tsichritzis, D. 1999. Re-engineering the university, Communications of the ACM, Vol. 42, Nr. 6, pp.93-100.

University of Pretoria. 2001. Telematic learning and education innovation, (Online).

http://www.up.ac.za/telematic.

WebCT 2000. WebCT Overview 2000, Lighthouse Publishers, Johannesburg.

Whalen, T. and Wright, D. 2000. The Business Case for Web-Based Training, Artech House, London. 